\title{
A five-year retrospective study on patterns of casuistry and insights on the current status of wildlife rescue and rehabilitation centers in Chile
}

\author{
Francisca Romero ${ }^{1}$, Angelo Espinoza ${ }^{2}$, Nicole Sallaberry-Pincheira ${ }^{3}$ and Constanza Napolitano ${ }^{4,5^{*}}$ (D)
}

\begin{abstract}
Background: Human activities are permanently threatening wildlife. Wildlife Rescue and Rehabilitation Centers (WRRC) have served for the rescue, rehabilitation and reinsertion of affected and recovered animals.

Methods: We reviewed the casuistry of five wildlife rescue and rehabilitation centers in Chile over 5 years, and described the main causes of admission, most affected taxonomic groups and final outcomes of the admitted individuals, shedding light into general patterns and relevant factors currently affecting wildlife in Chile. To understand the current work and status of WRRC system in Chile, we also conducted a qualitative survey to WRRC personnel and Agricultural and Livestock Service (SAG) regional offices regarding their operation.

Results: A total of 3418 cases of animals admitted to WRRC were obtained; 95.3\% corresponded to native species. Of native animal cases, $86.0 \%$ corresponded to birds, $12.3 \%$ were mammals and $1.7 \%$ reptiles. Trauma was the most frequently observed cause of admission in all three native fauna groups (35.8\% in birds, $23.2 \%$ in mammals, $27.8 \%$ in reptiles).

Conclusions: WRRC are a tool for conservation and education of wild animal species in Chile, however WRRC and SAG regional office personnel highlighted several deficiencies in the current system and suggested opportunities for improvement. The current WRRC system needs modernization and financial support from the Chilean state to fulfil their relevant mission.
\end{abstract}

Keywords: Fauna, Rehabilitation, Anthropogenic causes

\section{Background}

Human activities such as habitat loss and fragmentation, overexploitation of natural resources, expansion of human settlements, invasion of exotic species, among others, are permanently threatening wildlife. These activities cause road accidents, poisonings, burns, electric shocks, orphanage, hunting accidents, shooting practices or military maneuvers [1], interactions between carnivores and humans,

\footnotetext{
* Correspondence: cnapolit@uchile.cl

${ }^{4}$ Instituto de Ecología y Biodiversidad (IEB), Santiago, Chile

${ }^{5}$ Laboratorio de Ecologia Molecular, Departamento de Ciencias Ecológicas,

Facultad de Ciencias, Universidad de Chile, Las Palmeras 3425, Ñuñoa,

Santiago, Chile

Full list of author information is available at the end of the article
}

interactions with domestic dogs and cats, including attacks and transmission of diseases [2, 3, 4].

Wildlife rehabilitation is defined as the temporary care of injured, diseased, and displaced indigenous animals and the subsequent release of healthy animals to appropriate habitats in the wild [5]. Treating injured wildlife to return them to their original function, will allow individual animals to reproduce and contribute to their population [6]. Wildlife Rescue and Rehabilitation Centers (WRRC) have served for the recovery of individuals (ex situ conservation) to their release for in situ conservation $[7,8]$, as a tool for conservation education and to monitor ecosystem health [5].

WRRC in Chile are assigned the task of rescuing and rehabilitating affected wild animals. They are considered 
places of transit for the subsequent animals released back into the wild [9]. WRRC in Chile have been created by universities, NGOs and private organizations. They are autonomous entities, supervised by the Agricultural and Livestock Service (SAG, by its initials in Spanish), a governmental agency which grants the corresponding permits for their legal operation. To date, there are 22 WRRC registered in SAG (according to SAG web page, last update 19.11.2018). These centers are a tool for conservation of wildlife in Chile because they fulfill the role of rescue, rehabilitation and reinsertion of affected animals to their original habitats [7], allowing them to reproduce and contribute to their populations. They also have a valuable contribution to conservation by conducting environmental education and raising awareness in society.

Here, we aimed to describe general patterns of casuistry of five wildlife rescue and rehabilitation centers in Chile over 5 years. We reviewed the centers' records and described the main causes of admission, most affected taxonomic groups and final outcomes of the admitted individuals. During the study, we were faced with several difficulties with data collection and standardization and deficiencies in data quality. In order to better understand underlying causes and the current work and status of WRRC system in Chile, we also conducted a qualitative survey to WRRC personnel and Agricultural and Livestock Service (SAG) regional offices. We discuss strengths and deficiencies of WRRC operation in Chile and opportunities for improvement, based on our experience and the vision of professionals directly working in the field. We draw the attention to these concerns with the aim to place them on the table for further discussion and as guidelines for WRRC advancement in Chile.

\section{Methods}

During 2016, at the time of this study there were 23 WRRC registered in SAG. We visited eleven centers; only six allowed us access to their databases, others stated they were not able to participate in this study. Only five of the visited centers had enough information to be included in this study. These centers were: (i) Center for Rescue and Rehabilitation of Marine and Coastal Fauna, Iquique Municipality, (ii) Veterinary Hospital, Universidad Santo Tomás, Viña del Mar, (iii) National Zoo Rehabilitation Center of Native and Exotic Fauna, (iv) Wildlife Rehabilitation Unit, Universidad Andrés Bello/Buin Zoo (UFAS), (v) Rehabilitation Center for Wildlife, Universidad Austral de Chile (CEREFAS) (Fig. 1). Non-native species centers were excluded from this study.

Data was obtained directly from the clinical records (entry forms) of each animal admitted between 2011 and 2015 in each of these WRRC. The information was sorted and classified in a unified database, including variables such as: (i) common and scientific names; (ii) type of species (native, alien, exotic pet), (iii) taxonomic group (class, order, family), (iv) conservation status (according to IUCN), (v) type of donor, responsible for taking the animals to rehabilitation centers; (vi) sex and age group, homologized to different categories of infant development based on international standards [10]; (vii) cause of admission to centers; to unify criteria these were classified as proposed by the International Wildlife Rehabilitation Council [11]; (viii) cause of egress/ outcome.

All data analyzed was obtained from the best information available in the clinical records of each center. There is no national standardization of registry forms or categories for clinical records, thus data in most cases was homologized to categories from international standards by the US National Wildlife Rehabilitation Association (NWRA) and the International Wildlife Rehabilitation Council (IWRC) $[10,11]$ to comprise a unified database for further analysis. Alien species and exotic pets were excluded from these analyses.

During the same period, we conducted an anonymous qualitative survey to the veterinarians in charge of WRRC $(\mathrm{n}=11)$ and to the chiefs of the division of wildlife at SAG regional offices $(n=6)$. The aim of these surveys was to obtain their impressions and opinions on the positive and negative aspects of WRRC operation and to suggest ideas to improve the current WRRC system in Chile.

\section{Results}

A total of 3418 cases of animals admitted to five WRRC were obtained (Table 1). 95.3\% corresponded to native species (3256 cases, Additional file 1: Table S1), 1.9\% to alien species, $2.1 \%$ were exotic pets and $0.7 \%$ non-identified species.

Alien species corresponded mainly to rock dove ( $\mathrm{Co}$ lumba livia domestica; paloma doméstica) (42.2\%) and house sparrow (Passer domesticus; gorrión) (37.5\%). Exotic pets corresponded mainly to Argentine tortoise (Chelonoidis chilensis; tortuga terrestre argentina, illegal exotic pet, CITES Appendix II) (27.4\%) and red-ear turtle (Trachemys scripta; tortuga de orejas rojas) (9.6\%).

\section{Taxonomic groups}

Of 3255 total native animal cases, $86.0 \%$ corresponded to birds (2801 cases), $12.3 \%$ (401 cases) were mammals and $1.7 \%$ reptiles (54 cases) (Additional file 1: Table S1). Within birds, the order Falconiformes was the most affected (18.9\%), followed by Psittaciformes (14.7\%), Charadriiformes (14.1\%), Strigiformes (13.8\%), Pelecaniformes (8.9\%), Accipitriforme (8.8\%), Spheniciformes (5.1\%), Passeriformes (4.3\%) and other least represented orders (Fig. 2, 


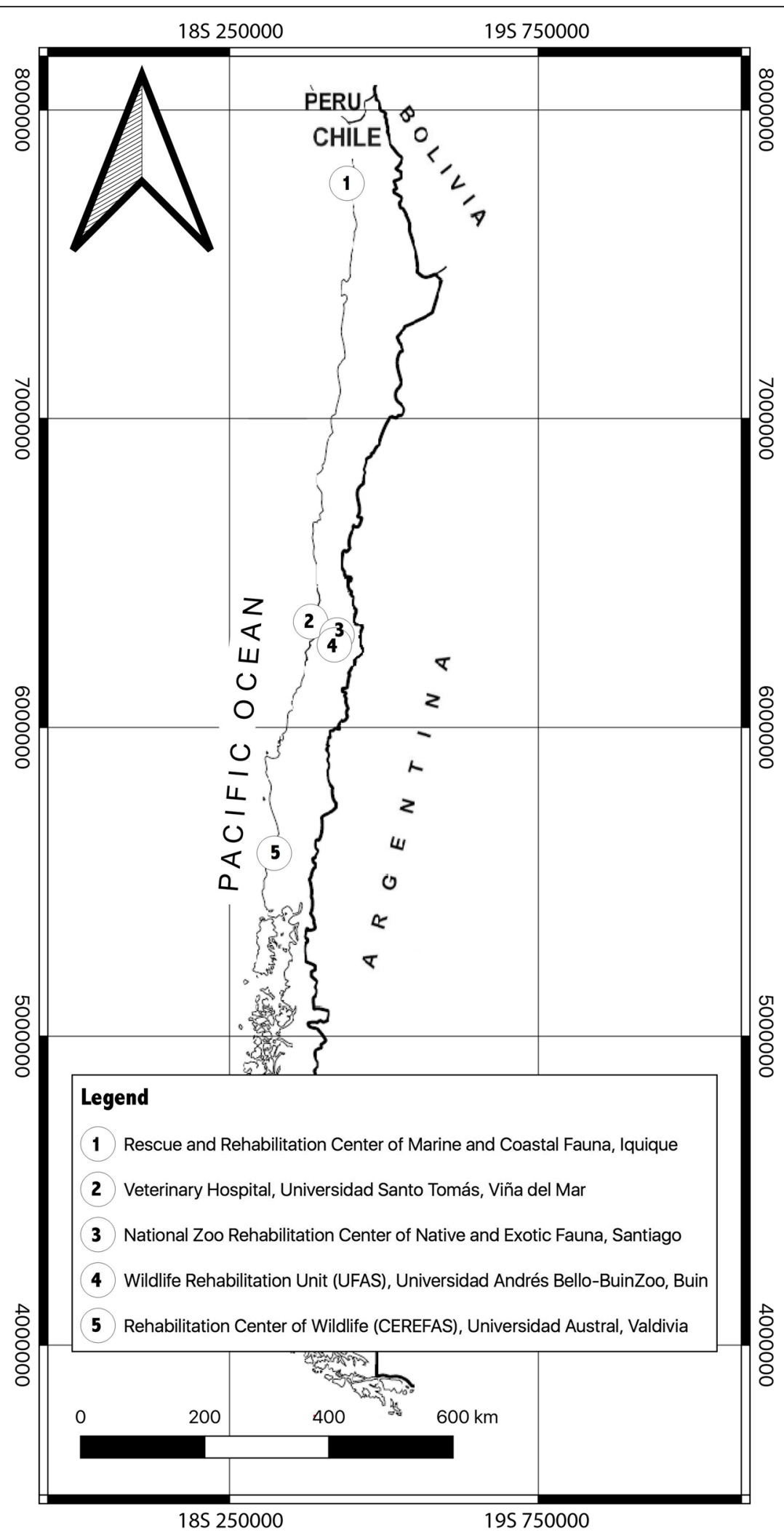

Fig. 1 (See legend on next page.) 
(See figure on previous page.)

Fig. 1 Wildlife Rescue and Rehabilitation Centers included in this study (Chile). 1. Center for Rescue and Rehabilitation of Marine and Coastal Fauna, Iquique Municipality; 2. Veterinary Hospital, Universidad Santo Tomás, Viña del Mar; 3. National Zoo Rehabilitation Center of Native and Exotic Fauna; 4. Wildlife Rehabilitation Unit, Universidad Andrés Bello/Buin Zoo (UFAS); 5. Rehabilitation Center for Wildlife, Universidad Austral de Chile (CEREFAS)

Additional file 1: Table S1). Most frequently admitted species were the slender-billed parakeet (Enicognathus leptorhynchus; loro choroy) (12.7\% of total birds), chimango caracara (Phalcoboenus chimango; tiuque) (12.0\%), and the kelp gull (Larus dominicanus; gaviota dominicana) (11.7\%).

For mammals, the most affected Orders were Carnivora (64.8\%) and Artiodactyla (22.2\%), followed by Rodentia (5.5\%), Didelphimorphia (3.5\%), Microbiotheria (3.5\%), Chiroptera (0.3\%) and Cetacea (0.3\%) (Fig. 2, Additional file 1: Table S1). Most affected species were the South American Sea Lion (Otaria byronia; lobo marino común) (22.9\% of total mammals), the Chilean pudu (Pudu puda; pudú) (22.2\%), and the Andean fox (Lycalopex culpaeus; zorro culpeo) (19.2\%).

In Reptiles, the Order Squamata (92.6\%) was the most affected, followed by Testudines (7.4\%) (Fig. 2, Additional file 1: Table S1). Most affected species were the Chilean longtailed snake (Philodryas chamissonis; culebra de cola larga) (81.5\% of total reptiles), the olive ridley sea turtle (Lepidochelys olivacea; tortuga olivácea) $(7.4 \%)$ and the Chilean iguana (Callopistes maculatus; iguana chilena) (5.6\%).

\section{Species conservation categories}

Of the native animals identified at the species level, $89.8 \%$ are classified according to the International Union for Conservation of Nature (IUCN) data as Least Concern (LC), followed by Near Threatened (8.5\%), Vulnerable (1.4\%), Endangered (0.3\%) and Data Deficient $(0.1 \%)$. Threatened species most frequently received were, in the category Vulnerable: Humboldt penguin (Spheniscus humboldti; pingüino de Humboldt), guigna (Leopardus guigna, güiña), olive ridley sea turtle (Lepidochelys olivacea; tortuga olivácea); Endangered: Peruvian tern (Sternula lorata; gaviotín chico), long-tailed chinchilla (Chinchilla lanigera; chinchilla de cola larga).

\section{Type of donor}

In relation to who delivers animals to the centers, $46.4 \%$ of the animals were taken by SAG, $28.0 \%$ by the general public, $5.3 \%$ by other institutions such as municipalities, private companies or the army, $5.2 \%$ by policemen, $4.3 \%$ by the National Fisheries Service (SERNAPESCA, by its initials in Spanish), 0.3\% were derived from another rehabilitation center and $0.2 \%$ were taken by the National Forestry Corporation (CONAF, by its initials in Spanish). Finally, $10.4 \%$ had no recorded donor.

Specifically in the case of exotic pets, the type of donor associated to their reception at WRRC is $50.0 \%$ by the general public (particular donors, presumably owners), $23.8 \%$ undetermined (non-recorded donor), 21.4\% by SAG and $4.8 \%$ by policemen, SERNAPESCA or zoos.

\section{Sex}

Of all native animals received, $81.1 \%$ had no determined sex according to the centers' records. This corresponds to $88.5 \%$ of birds, $85.2 \%$ of reptiles and $28.7 \%$ of mammals for which sex could not be determined or was not recorded. For birds, mammals and reptiles for which sex was determined, the most affected sex was males (52.6, 57.0 and $75.0 \%$, respectively).

In mammals, for which sex information is mostly available, specifically in the Order Carnivora, $63.9 \%$ of the individuals were males and $36.1 \%$ females. For the different families, the proportions are: Otariidae 79.0\% male and $21.1 \%$ female; Canidae $55.0 \%$ male and $45.0 \%$ female; Felidae $56.3 \%$ male and $43.8 \%$ female; Mustelidae

Table 1 Centers included in this study, number of cases analyzed between 2011 and 2015, and proportion of data contribution to total database

\begin{tabular}{lll}
\hline Wildlife Rescue and Rehabilitation Center & Number of cases & \% \\
\hline $\begin{array}{l}\text { Rescue and Rehabilitation Center } \\
\text { of Marine and Coastal Fauna, lquique }\end{array}$ & 50 \\
$\begin{array}{l}\text { Veterinary Hospital, Universidad } \\
\text { Santo Tomás, Viña del Mar }\end{array}$ & 1065 \\
$\begin{array}{l}\text { National Zoo Rehabilitation Center } \\
\text { of Native and Exotic Fauna, Santiago }\end{array}$ & 1183 \\
$\begin{array}{l}\text { Wildlife Rehabilitation Unit (UFAS), } \\
\text { Universidad Andrés Bello-BuinZoo, Buin }\end{array}$ & 186 \\
$\begin{array}{l}\text { Rehabilitation Center for Wildlife } \\
\text { (CEREFAS), Universidad Austral, Valdivia }\end{array}$ & 934 \\
Total & 34.6 \\
\hline
\end{tabular}






$\square$ Mammals $\square$ Reptiles $\square$ Birds

Fig. 2 Most affected taxonomic groups and orders in studied Wildlife Rescue and Rehabilitation Centers (2011-2015)

$77.8 \%$ male and $22.2 \%$ female. In the Order Artiodactyla (Cervidae Family), the opposite trend was found; 56.1\% of the animals were females and $43.9 \%$ males.

\section{Age group}

According to the centers' records, of all native animals received, age could not be determined or was not recorded in $38.3 \%$ of the cases $(39.6 \%$ of birds, $27.7 \%$ of mammals and $48.1 \%$ of reptiles). For animals for which age was determined, age proportions in birds admitted to the centers were: $2.8 \%$ neonatal, $3.4 \%$ chick, 8.3\% fledgling, $33.5 \%$ juvenile, $1.2 \%$ subadult and $50.7 \%$ adult. For mammals, $2.4 \%$ were neonate, $15.5 \%$ puppy, $39.7 \%$ juvenile, $1.4 \%$ subadult, $40.7 \%$ adult, $0.3 \%$ senile. For reptiles, 3.6\% were young, 39.3\% juveniles and 57.1\% were adults.

\section{Causes of admission}

Trauma (34.1\%) was the most frequently observed cause of morbidity in all three fauna groups $(35.9 \%$ in birds, $23.2 \%$ in mammals and $27.8 \%$ in reptiles) (Fig. 3, Additional file 1: Table S2). In birds, $88.3 \%$ of trauma cases corresponded to unspecific osteopathies, lesions, injuries and wounds, while specifically identified were $5.3 \%$ gunshot wounds, $2.2 \%$ motor vehicle collisions, $1.6 \%$ kite string injuries and $1.4 \%$ electrocutions, among other less frequent causes (Fig. 3, Additional file 1: Table S2). In mammals, $63.4 \%$ of trauma cases corresponded to unspecific osteopathies, lesions, injuries and wounds, while specifically identified were $21.5 \%$ motor vehicle collisions, $13.9 \%$ snare trap injuries and $1.1 \%$ gunshot wounds. In reptiles, $86.7 \%$ of trauma cases corresponded to unspecific osteopathies, lesions, injuries and wounds,




while specifically identified were $13.3 \%$ motor vehicle collisions.

Regarding other causes of admission, in birds, the second most frequent was inappropriate possession (9.1\%), followed by orphanhood (4.6\%), systemic disorder $(4.5 \%)$, found (3.6\%), environmental cause $(2.5 \%)$ and animal interaction (1.8\%), among other less frequent causes (Fig. 3, Additional file 1: Table S2). Of the cases related to inappropriate possession in birds, $45.3 \%$ were confiscation and $15.2 \%$ voluntary delivery. $79.7 \%$ of inappropriate possession cases corresponded to psittacine birds, and species such as the burrowing parrot (Cyanoliseus patagonus; loro tricahue), slender-billed parakeet (Enicognathus leptorinchus; loro choroy) and Austral parakeet (Enicognathus ferrugineus; loro cachaña) constituted $41.4 \%$ of all confiscations. Environmental causes (2.5\%) corresponded mainly to $52.1 \%$ oiled and $45.1 \%$ intoxicated animals. For animal interaction cases (1.8\%), $57.1 \%$ were attacks by domestic dogs, $22.5 \%$ attacks by domestic cats and $20.4 \%$ attacks by wild species (Fig. 4).

In mammals, the second most frequent cause of admission was systemic disorder (12.7\%) followed by animal interaction (12.0\%), inappropriate possession (4.7\%), found (3.7\%), orphanhood (3.5\%), arrives dead (3.0\%) and environmental (0.5\%), among other less frequent causes (Fig. 3, Additional file 1: Table S2). For animal interaction cases (12.0\%), 100.0\% were attacks by domestic dogs, being the Chilean pudu (Pudu puda; pudú) the most affected species (70.8\%, 34 of 48 cases), followed by the coypu (Myocastor coypus; coipo) (10.4\%), and grey fox (Lycalopex griseus; zorro chilla) (10.4\%) among other less frequent species (Fig. 4).

In reptiles, the second most frequent admission cause was inappropriate possession (9.3\%), followed by found (9.3\%), animal interaction (1.9\%) and systemic disorder (1.9\%) (Figs. 3, 4, Additional file 1: Table S2).

The cause of admission was neither determined nor specified in the centers' records for $28.0 \%$ of birds, $24.2 \%$ of mammals and $25.9 \%$ of reptiles. Animals in good condition constituted $7.6 \%$ of admitted birds, $11.2 \%$ mammals and $24.1 \%$ reptiles.

Specifically identified human-related causes (such as gunshot, motor vehicle collision, kite string, electrocution, barbed wire, fishing nets, inappropriate possession, oiled, intoxicated, and domestic dog and cat attack), altogether encompassed $24 \%$ of specified admissions in birds, $34 \%$ in mammals and $20 \%$ in reptiles (calculated from all cases where a cause of admission was effectively determined, including unspecific trauma).

\section{Case outcomes}

Regarding the outcomes of the centers' cases, in birds, $47.8 \%$ of the animals died in the centers $(23.2 \%$ died, $24.6 \%$ euthanized), $19.5 \%$ were released, $17.0 \%$ were transferred to other centers and $0.1 \%$ escaped (Fig. 5). In $15.6 \%$ of the cases the outcome was not recorded in the centers' entry forms. In mammals, $45.4 \%$ died in the centers (34.9\% died, $10.5 \%$ euthanized), $25.4 \%$ were released, $7.7 \%$ were transferred to other centers and $1.0 \%$ escaped. In $20.5 \%$ of the cases the outcome was not recorded. For reptiles, $40.7 \%$ were released, $27.8 \%$ died in the centers (20.4\% died, $7.4 \%$ euthanized) and $14.8 \%$ were transferred to other centers. In $16.7 \%$ of the cases the outcome was not recorded (Fig. 5).

\section{Qualitative surveys to WRRC and SAG personnel}

We recorded WRRC and SAG personnel opinions on positive and negative aspects of their own current operation and that of their counterpart. Both shared several core ideas, such as the lack of government funding, the need for capacity building and revision of fiscalization procedures (Additional file 1: Table S3). They also suggested ideas to improve the current WRRC system in Chile, both groups sharing several recommendations such as creating a national online database, nation-wide

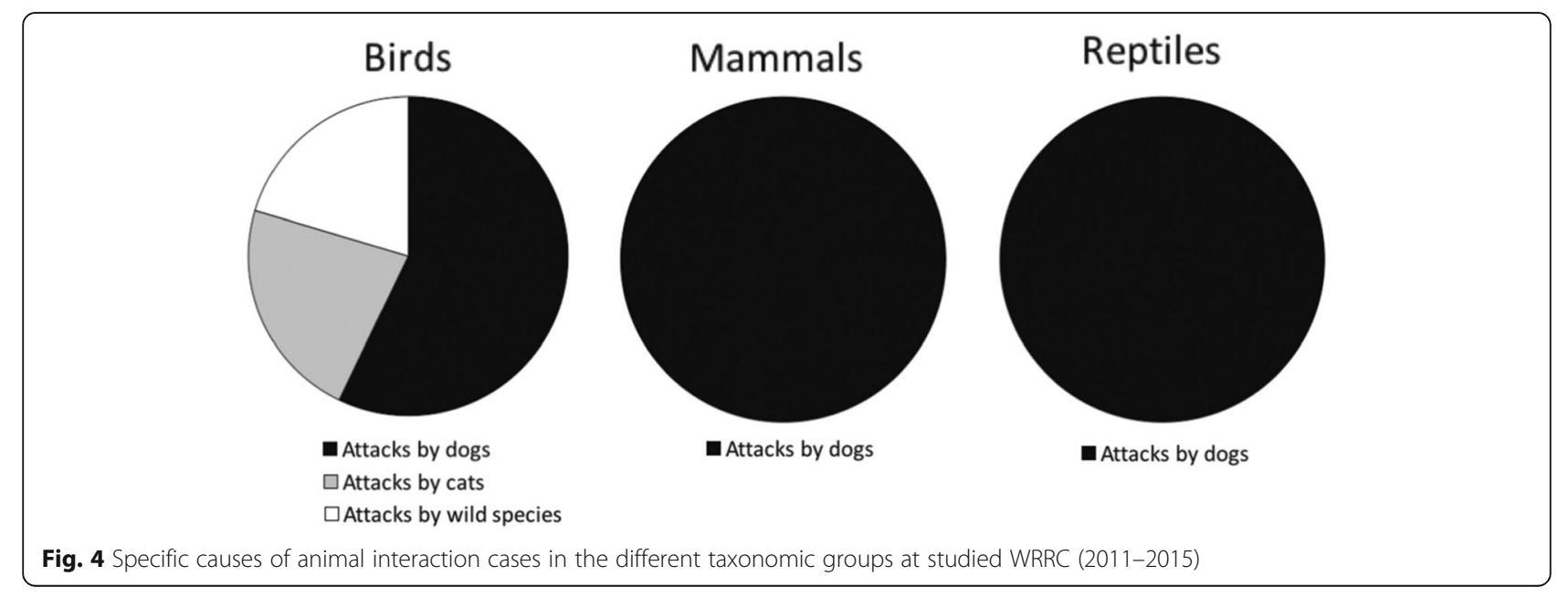



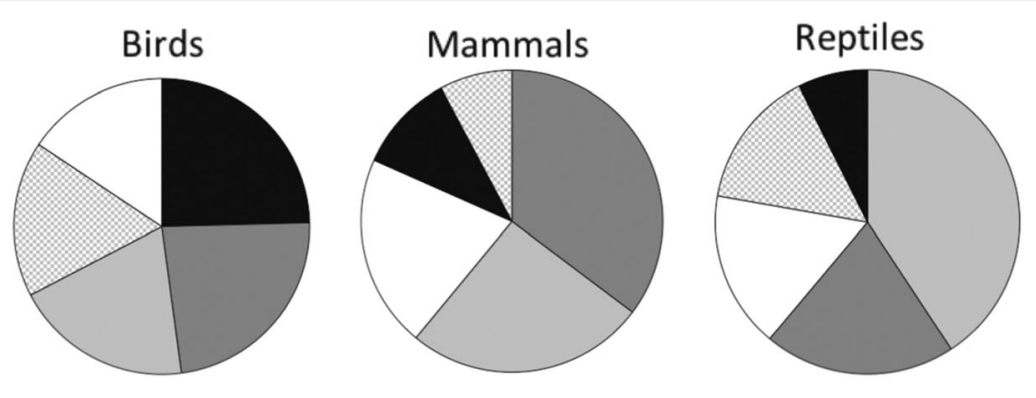

Euthanized $\square$ Died $\square$ Released $\quad \square$ Transferred to other centers $\square$ Not recorded

Fig. 5 Case outcomes for the different taxonomic groups in studied Wildlife Rescue and Rehabilitation Centers (2011-2015)

standardized protocols and criteria, and improving communication and interaction between WRRC and SAG (Additional file 1: Table S4). Main ideas are further elaborated in the Discussion.

\section{Discussion}

Birds were the most affected native species group admitted to WRRC, followed by mammals and in much lower proportion, reptiles. A similar pattern was described in previous studies [12-14]. In birds, the order Falconiformes was the most affected due to the large amount of Chimango caracara (Phalcoboenus chimango; tiuque) that are admitted to WRRC (61.1\% of the Falconiformes received). Chimango caracaras are anthropophilic raptors that are easily observed in urban settings [15], and therefore might be easily found by humans which may increase their occurrence in rehabilitation centers. Furthermore, due to their increased interaction with humans they might have a greater probability to be negatively affected by them, for example, being run over by vehicles in urban streets or highways due to their scavenging behaviors [16]. This could imply a bias in the databases, because the species received in the centers are also those highly related to humans and the places they inhabit, therefore, it is more likely that when affected, animals are found and taken to a rehabilitation center more often than other species with less interaction with humans or human-dominated landscapes [17]. In mammals, carnivores were the most affected order, probably because of the varied spacing strategies adopted by different carnivores [18]. Raptors and carnivores are ecologic keystone species and important regulators of rodent populations. A decrease in raptor or carnivore populations would result in increased rodent populations and possibly increased rodent-associated zoonotic infections and public health implications [5].

SAG, followed by the general public, were the two main donor groups, accounting for the largest proportion of animals delivered to WRRC. This result confirms the close relationship that SAG and WRRC have and also highlights the importance of educating and raising general public awareness.

Sex was unfrequently recorded, especially for birds and reptiles. Sex determination is not easy for some species; Some birds have no sexual dimorphism, and it is directly related to the experience of the clinician. For those animals for which sex was determined, males were more affected than females in all three taxonomic groups. In carnivores, males tend to disperse more and take more risks than females [19]. Specifically in the order Artiodactyla (Pudu puda) the opposite was true, being females the highest proportion of admitted animals. Female pudus take many months per year to produce and rear their offspring, with high gestation and lactation energy costs [20], making them more vulnerable to threats [21].

Age could not be determined or was not recorded in a high proportion of cases, especially for reptiles. In reptiles, the age of an individual may be more difficult to determine by untrained personnel. Alternatively, WRRC may not take the time to record this data in entry forms for some taxa for which it may be more laborious. Age categories are not nationally standardized, being homologation to international categories laborious and error-prone. WRRC in Chile should use international standards for all categories recorded in entry forms (e.g. age group, cause of admission) $[10,11]$ so that comparisons can be made across centers.

In all taxa, the most frequent age after adults were juveniles, a stage where the animals tend to disperse in search of a territory to settle [22]. The age of admission is also usually associated with the season; Orphanhood is more frequent during spring and summer [12].

The most common cause of admission to WRRC in all three native fauna groups was trauma. This pattern agrees with that obtained by Basso [12]. Within this category, a high proportion in all three groups corresponds to unspecific classifications of trauma (osteopathies [fractures, dislocations], lesions, injuries and wounds), which do not specify the real cause of admission, but rather clinical signs showed by the animals. This unspecific classifications of trauma are 
inaccurate and do not confirm the primary cause affecting the animals. Therefore, within the category of unspecific trauma, human-related underlying causes may or may not be involved.

Only for those trauma cases were a specific direct cause was recorded (e.g. gunshot, motor vehicle collision, kite string, electrocution, barbed wire) we may be able to draw conclusions. In the case of mammals, motor vehicle collisions (22\%) and snare traps (14\%) had relatively high frequencies of occurrence. In birds, most trauma categories are unspecific. In reptiles, motor vehicle collisions encompassed $13 \%$ of all trauma cases In reptiles, motor vehicle collisions encompassed $13 \%$ of all trauma cases, similar to other studies [23].

Causes of admission recorded as undetermined or unspecific encompassed a high proportion of total data.

Regarding animal interaction cases, in birds, both dogs and cats were implicated in attacks. In mammals, all attacks were caused by domestic dogs, being the most affected species the Chilean pudu. Our results agree with those obtained by Silva-Rodríguez et al. [24], who reported attacks by dogs were frequently recorded as the main cause of death for pudus in two wildlife rescue centers and two rural areas in Bio-Bio, Los Rios and Los Lagos (Chiloe Island) regions in southern Chile. Records classified as attacks by domestic dogs and cats to fauna -relevant in the current context of the new Responsible Pet Ownership Law in Chile- may be underestimated, because they only include cases where a person witnessed the attack and/or when the injuries are evidently or most likely caused by them [6].

Inappropriate possession of animals was recorded in low frequency in this study and its relationship with wildlife trafficking in Chile cannot be proved. Legal hunting and commercialization of Chile's vertebrates was never as high as in most other Latin American nations [25, 26]. In 1993, the imposition of stringent new regulations in Chile almost completely ceased these practices for all native species, except for a small number of birds [26]. Native wildlife in Chile has full governmental protection. Hunting and commercialization of native species and the import and possession of exotic wildlife (including exotic pets) in Chile is regulated under Law 19,473 [9]. This law considers full protection to species included in international conventions, such as CITES (Convention on International Trade in Endangered Species of Wild Fauna and Flora) and CMS (Convention on the Conservation of Migratory Species of Wild Animals). However, minor clandestine traffic may still take place for some species fully protected on paper, mainly due to problems with enforcement of current strict regulations [26].

Regarding causes of discharge, a high proportion of deaths corresponded to cases of oiled or intoxicated animals, which are clinically high-difficulty cases for the complete recovery of the animals. Animals are transferred to specialized centers to continue their rehabilitation, but also to exhibition and/or reproduction centers in the case of animals for which release is impossible due to unsuitable physical or mental conditions [12]. Animals transferred to other centers currently do not have a unique follow-up tracking number, thus, although in low proportion, may have caused case duplications in our database.

Most animals released back to the areas from which they were rescued, are frequently not monitored after release, due to a lack of funding and also the need of WRRC to prioritize among multiple functions. Post-release survival studies are crucial to assess the success of often expensive and time-consuming rescue and rehab managements. Often times, animals are not released but are translocated, which means they are released in areas or regions different from the original area from where they were rescued. Translocations are not recommended by the IUCN due to the risk associated with introducing diseases into new areas [27] and disrupting ecological balances, among other reasons. However, if they need to be done, an initial study needs to be conducted and the individuals have to be monitored after introduction, following the IUCN/SSC recommended guidelines [28]. Release policies should be designed to minimize the potential for disease introduction into the wild and the harm to wild populations and the environment [5]. Also, in some WRRC in Chile, domestic and exotic pet attention is conducted in the same facilities where wildlife is served, which may pose a high risk for pathogen spill over from these groups to admitted wildlife. Most releases are conducted without pre-release screening for pathogens or specific diseases through either serology or PCR. Infectious contagious diseases within WRRC are dangerous for wild recipient populations, as well as for admitted wildlife [29].

Undetermined or unspecified data in the centers' records encompasses a high proportion of all cases, hindering the possibility of examining interesting casuistry details, such as the most common infectious diseases diagnosed, intoxicants or direct causes of admission. Incomplete entry forms are frequently due to a lack of time during high demand, strenuous working days with a small staff team, where often times personnel must prioritize the health of the animal over completing forms [14]. Complete details for each case should be registered in the centers' records whenever known, and this should be promoted and encouraged by SAG, given the advantages of counting on such a valuable macroscale national database. Training of WRRC personnel should strongly point out the relevance of accurate and complete clinical records as a major contribution of WRRC to national rescue and rehabilitation statistics.

SAG requires each WRRC to deliver semi-annual declarations containing only information on the stock of 
animals in each center at the date of declaration. This declaration does not require the identification of different individuals, neither clarifications on the causes of income, discharge, or other relevant casuistry data. Retrieved only from SAG declarations, a significant loss of casuistry information occurs. However, most centers keep their own entry forms and clinical details in paper files, including only the information each of them considers pertinent. Consequently, there are different types of entry forms and clinical files, currently hindering the unification of information. Given that WRRC are autonomous entities, SAG does not have free access to their internal databases. In this study, we had full SAG support to conduct our revision, however only six of eleven visited centers allowed us access to their entry forms.

Not all regions have a wildlife rehabilitation center (which may be causing unwanted translocations). We propose the creation of Primary Care Centers throughout the country, which may carry out the clinical rehabilitation of the specimens who are then derived, according to their possibilities of survival and reintegration, to centers specialized in this task, as is carried out in Ecuador and Colombia [30].

\section{Conclusions}

There is a need to create a unified, online digital database for all WRRC throughout the country, with one universal entry form, and unique animal tracking numbers for effective individual follow-up. This would prevent the lose of valuable information and facilitate long-term trend studies for a better understanding on the impacts of human activities and climate change on rescued wildlife [31]. It would also be useful to standardize the system by generating national guidelines and increase minimum optimal requirements for WRRC in Chile. All personnel working in WRRC should be trained in issues of conservation practice.

Most WRRC in Chile do not receive monetary support to operate. If we want to raise the standards of wildlife primary attention in Chile and fulfil agreed national objectives, WRRC should have a baseline financial support from government agencies, to aid the extensive work carried out by professionals and volunteers.

Wildlife Rescue and Rehabilitation Centers are on the forefront of human impacts and ecological changes in the landscapes, being usually the first to receive animals affected by natural disasters or epidemics, thus they can serve as a nationwide early warning system for monitoring ecosystem health. Most of them provide a valuable conservation education service in society. These centers are in a unique position to advance knowledge on ex-situ conservation in Chile, however substantial improvements in the system should be implemented.

\section{Additional file}

Additional file 1: Table S1. Taxonomic origin and frequency of native species admitted to WRRC studied between 2011 and 2015. Table S2. Causes of admission of native species to WRRC studied between 2011 and 2015. Table S3. Qualitative survey on WRRC and SAG operation: Core ideas per group. Table S4. Qualitative survey: Suggested ideas to improve WRRC system in Chile, core ideas per group. (DOCX 45 kb)

\section{Abbreviations}

CONAF: National Forestry Corporation; SAG: Agricultural and Livestock Service; SERNAPESCA: National Fisheries Service; WRRC: Wildlife Rescue and Rehabilitation Center

\section{Acknowledgements}

We gratefully acknowledge the WRRC who shared their data with us and made this study possible: Center for Rescue and Rehabilitation of marine and coastal fauna of the Municipal Development Corporation of Iquique, specially to Mr. Jesús Medina; Veterinary Hospital, Universidad Santo Tomás, Viña del Marm, specially to Pablo Salah; Rehabilitation Center for native and exotic fauna, National Zoo, special thanks to Alejandra Montalba; Wildlife Rehabilitation Unit (UFAS), Universidad Andrés Bello/Buin Zoo and Rehabilitation Center for Wildlife; Universidad Austral de Chile (CEREFAS). We also thank those WRRC who received us and gave us valuable feedback: Metrenco Veterinary Rehabilitation Center, Guanacos Rehabilitation Center in Coquimbo, University of Antofagasta Rehabilitation Center, Cascada de las Ánimas Rehabilitation Center, Reptile Rehabilitation Center, Wildlife

Rehabilitation Center CODEFF. We are grateful to all the regional SAG offices. We thank SAG central office in Santiago, Departamento de Vida Silvestre, División de Protección de los Recursos Naturales Renovables, specially to Marcela Alcaide.

\section{Authors' contributions}

FR visited the centers, collected the data, generated the database, generated the results and drafted the study. AE revised, edited the study and contributed data. NS revised, edited and contributed data. CN directed the study, guided, edited, corrected and contributed with scientific structure. All authors read and approved the final manuscript.

\section{Funding}

C.N. acknowledges support from CONICYT FONDECYT Iniciación 11150934, Morris Animal Foundation (MAF) Fellowship Training Award D15ZO-413, National Geographic Society Conservation Trust C309-15, Mohamed bin Zayed Species Conservation Fund 152510351

\section{Availability of data and materials}

All data generated or analysed during this study are included in this published article and its supplementary information files.

Ethics approval and consent to participate Not applicable.

\section{Consent for publication}

Not applicable.

\section{Competing interests}

This study was conducted with the support and collaboration of the Agricultural and Livestock Service (SAG) of Chile.

\section{Author details}

${ }^{1}$ Programa Protectores de la Güiña, Santiago, Chile. ${ }^{2}$ CEREFAS, Instituto de Ciencias Clínicas y Programa de Investigación Aplicada en Fauna Silvestre, Facultad de Ciencias Veterinarias, Universidad Austral de Chile, Valdivia, Chile. ${ }^{3}$ UFAS, Escuela de Medicina Veterinaria, Facultad Ciencias de la Vida, Universidad Andres Bello, Santiago, Chile. ${ }^{4}$ Instituto de Ecología y Biodiversidad (IEB), Santiago, Chile. ${ }^{5}$ Laboratorio de Ecologia Molecular, Departamento de Ciencias Ecológicas, Facultad de Ciencias, Universidad de Chile, Las Palmeras 3425, Ñuñoa, Santiago, Chile. 
Received: 10 May 2019 Accepted: 28 August 2019

Published online: 09 September 2019

\section{References}

1. Aprile G, Bertonatti C. Manual sobre Rehabilitación de Fauna. Boletín técnico N 31. Fundación Vida Silvestre Argentina (FVSA) 1996;111 p.

2. Montesdeoca N, Calabuig P, Corbera J, Orós J. Causes of admission for raptors to the Tafira wildlife rehabilitation center, gran Canaria Island, Spain: 2003-2013. J Wildl Dis. 2016:52(3).

3. Rodríguez B, Rodríguez A, Siverio F, Siverio M. Causes of raptor admissions to a wildlife rehabilitation Center in Tenerife (Canary Islands). Journal of Raptor Research Tenerife. 2010;44(1):30-9.

4. Tala C, Guerrero S, Avilés R, Stutzin M. Especies amenazadas de extinción ( $1^{\circ}$ Edición). Santiago: Grafhika. 2009.

5. Sleeman J. Use of wildlife rehabilitation centers as monitors of ecosystem health. En: Fowler's zoo and wild animal medicine current therapy. St. Louis, Missouri: Saunders Elsevier. 2008:97-104.

6. Loyd K, Hernandez S, McRuer D. The role of domestic cats in the admission of injured wildlife at rehabilitation and rescue centers. Wildl Soc Bull. 2017;41(1):55-6.

7. Pozo N. Valorización Técnico-Económica para la Construcción y Operación de un Centro de Rehabilitación de Fauna Silvestre en la Reserva Biológica Huilo-Huilo, Comuna de Panguipulli, Región de Los Ríos, DMV thesis. Universidad Mayor, Santiago, Chile. 2014.

8. Stutzin. Centros de Rehabilitación y Reproducción de fauna nativa. En: Biodiversidad de Chile. Santiago: Ocho libros. 2008:568-569.

9. Law N¹9.473. Diario oficial de la República de Chile. Santiago, Chile, 7 de diciembre de 1998.

10. Miller EA (Ed). Minimum standards for wildlife rehabilitation. 3rd Edition, US National Wildlife Rehabilitation Association (NWRA) and the International Wildlife Rehabilitation Council (IWRC), USA. 2000.76 pp.

11. International Wildlife Rehabilitation Council. In: Circumstances of admission. (Actualizada: 15 junio 2016). Theiwrc.org. 2013. http://www. theiwcr.org, https://theiwrc.org/?s=circumstances+of+admission for subordinate document.

12. Basso E. Estudio retrospectivo del centro de rehabilitación de fauna silvestre de la Universidad Austral de Chile (CEREFAS) durante el período 2005-2012 y propuesta de un sistema de gestión de base de datos. DVM thesis. Universidad Austral de Chile, Valdivia, Chile. 2014.

13. Nassar F, González C, Lozano I, Patiño X, Cuadros L. Protocolo general de manejo para el centro de recepción y rehabilitación de fauna silvestre del Dama. Revisión del funcionamiento de los Centros de Rehabilitación de fauna silvestre en Engativá. Colombia, Bogotá. 1998;2-45.

14. Peña E. Características de los Centros de Rehabilitación o Rescate de fauna silvestre chilenos, DMV thesis. Universidad de Concepción, Concepción, Chile. 2013.

15. Morrison JL, Phillips LM. Nesting habitat and success of the chimango caracara in southern Chile. Wilson Bull. 2000;112(2):225-32.

16. Lambertucci SA, Speziale KL, Rogers TE, Morales JM. How do roads affect the habitat use of an assemblage of scavenging raptors?. Biodivers Conserv. 2009;18:2063-74.

17. Spalding $M$, Forrester $D$. Disease monitoring of free-ranging and released wildlife. Journal of Zoo and Wildlife Medicine. 1993;24(3):217-80.

18. Dunstone N, Durbin L, Wyllie I, Freer R, Acosta Jamett G, Mazzolli M, Rose S. Spatial organization, ranging behavior and habitat use of the kodkod (Oncifelis guigna) in southern Chile. J Zool. 2002;257(1):1-11.

19. Bekoff M, Daniels TJ, Gittleman JL. Life history patterns and the comparative social ecology of carnivores. Annu Rev Ecol Syst. 1984;15:191-232.

20. Clutton-Brock T, Guinness F, Albon S. Red Deer behavior and ecology of two sexes. Wildlife behavior and ecology series. University of Chicago. 1982.

21. Silva-Rodríguez E, Aleuy OA, Fuentes-Hurtado M, Vianna JA, Vidal F, Jiménez JE. Priorities for conservation of the pudu (Pudu puda) in southern South America. Anim Prod Sci. 2011;51:375-7.

22. Pike $D$, Pizzatto $L$, Pike $B$, Shine R. Estimating survival rates of uncatchable animals: the myth of high juvenile mortality in reptiles. Ecology 89(3). The Ecological society of America. 2008:607-11.

23. Brown JD, Sleeman JM. Morbidity and mortality of reptiles admitted to the wildlife center of Virginia, 1991 to 2000. J Wildl Dis. 2002;38(4):699-705.

24. Silva-Rodríguez E, Verdugo C, Aleuy O, Sanderson J, Ortega-Solís G, OsorioZúñiga F, González-Acuña D. Evaluating mortality sources for the vulnerable pudu (Pudu puda) in Chile: implications for the conservation of a threatened deer. Oryx. 2009;44:97-103.
25. Sánchez A (2000) Tráfico illegal de fauna Silvestre. Fundamentos sobre rehabilitación en fauna silvestre. Colombia. 2000;(1)3:7-10).

26. Iriarte JA, Feinsinger $P$, Jaksic FM. Trends in wildlife use and trade in Chile. Biological Conservation 1997:81(1-2):9-20.

27. Kock RA, Woodford MH, Rossiter PB. Disease risks associated with the translocation of wildlife. Rev Sci Tech. 2010;29(2):329-50.

28. IUCN/SSC. Guidelines for Reintroductions and Other Conservation Translocations. Version 1.0. Gland, Switzerland: IUCN Species Survival Commission, viiii. 2013;57.

29. Brieva C. Rehabilitación. Fundamentos sobre rehabilitación en fauna silvestre. (pp. 3-6). Colombia. 2000a;(1)3:3-6.

30. Brieva C. Antecedentes y situación actual. Fundamentos sobre rehabilitación en fauna silvestre.(1)3. (pp. 3-6). Colombia. 2000b;(1)3:3-6.

31. Wendell M, Sleeman J M, Kratz G (2002) Retrospective study of morbidity and mortality of raptors admitted to Colorado state university veterinary teaching hospital during 1995 to 1998. J Wildl Dis. 2002;38(1):101-106.

\section{Publisher's Note}

Springer Nature remains neutral with regard to jurisdictional claims in published maps and institutional affiliations.
Ready to submit your research? Choose BMC and benefit from:

- fast, convenient online submission

- thorough peer review by experienced researchers in your field

- rapid publication on acceptance

- support for research data, including large and complex data types

- gold Open Access which fosters wider collaboration and increased citations

- maximum visibility for your research: over $100 \mathrm{M}$ website views per year

At BMC, research is always in progress.

Learn more biomedcentral.com/submissions 